hydrodynamical reasons. (The median spiral of a plectolophe is not a true parallel here, for it is a relatively short and rapidly tapering tube-a shape perfectly adapted to its function.) Finally, his interpretation leaves unexplained the characteristic form of spiralia-the closely-spaced whorls surrounding a wide central space - and their characteristic " moulding" to the shell; and it also leaves as an anomaly the close similarity (in these features) between spiriferoids and atrypoids.

As in most other branches of geology, here too the validity of our interpretations must be judged by the range of unexplained phenomena which they render intelligible. In the present state of knowledge of brachiopod morphology, I prefer to leave open the question of the jugum, since the only apparent alternative is to deprive a much wider variety of structures of any meaningful significance.

Sedgwick Museum,
CAmbridge.
3rd November, 1960.

M. J. S. RuDwick.

\title{
ON GRYPHAEA
}

SIR,--In a recent paper in this magazine (1959a) I sought to demonstrate that the evidence does not support Trueman's classic hypothesis on the gradual evolution of Gryphaea from Liostrea in the basal zones of the Lias. That part of my work based upon a statistical study of Gryphaea, which has a critical bearing on the hypothesis, has been questioned by Dr. K. A. Joysey (1959) on two grounds, involving technique and results respectively.

My choice of measurement of the periphery to assess the amount of coiling of the left valve is criticized because it is based upon the erroneous assumption that the left valve conforms to a perfect logarithmic spiral. No such assumption is necessary for the matter in question and I persist in my contention that length of the periphery provides an effective measure of coiling accurate enough to test Trueman's hypothesis. I shall try to demonstrate this. In fig. 1 of his 1922 paper Trueman gave drawings of four specimens from different horizons to illustrate his Liostrea-Gryphaea lineage, which one may reasonably presume he regarded as more or less modal, since otherwise the figure loses its point. I have made determinations of the ratio of the periphery (P) to length of right valve (R) of the Glamorgan gryphaeas from the angulata Subzone (fig. 1b) and a much higher horizon, queried gmuendense Subzone (fig. 1d). (The fact that the specimen of fig. $1 \mathrm{~b}$ is named as $G$. dumortieri does not affect the issue, since the whole figure purports to illustrate a gradual transition and is misleading in giving no hint that highly incurved gryphaeas occur commonly in the angulata Subzone (see below).) I have also determined the mean $P: \mathbf{R}$ ratio for my own collections from Glamorgan. The results are given below:

$$
\begin{aligned}
& \text { Trueman's fig. } 1 \mathrm{~b}(\mathrm{R}=3.00 \mathrm{~cm} \text {.) } \\
& \text { " fig. 1d ( } \mathrm{R} \text { not determinable since diagram of shell } 3.00 \\
& \text { "slightly reduced".) } \\
& \text { Personal collection: } \\
& \text { angulata Subzone (mean of total) . . . . . } 2.55 \\
& \Rightarrow \quad(\mathbf{R}=2 \cdot 9-3 \cdot 1 \mathrm{~cm} .) \quad . \quad 5 \quad 2 \cdot 67 \\
& \text { gmuendense Subzone (mean) } \quad . \quad \cdot \quad \cdot \quad \cdot \quad \cdot 2.67
\end{aligned}
$$

The ratio for the specimen of fig. $1 \mathrm{~b}$ is markedly at variance with my data; in fact highly incurved forms such as that illustrated in fig. 1d are the dominant element in all my angulata Subzone material from England and Wales, as anyone who cares to examine my collections may confirm.

Admittedly this simple method of comparison leaves something to be desired, but it is the best I can do in the absence of an original collection to refer to. It serves adequately, however, to illustrate the point I wish to make, namely that Trueman claimed striking changes in the adult organism which should be clearly revealed even using the periphery only as an approximate 
measure of coiling. In my experience in dealing with large assemblages of Gryphaea $I$ find this measurement, though admittedly not ideal, the most practicable one. At least it seems more refined than assessment of coiling

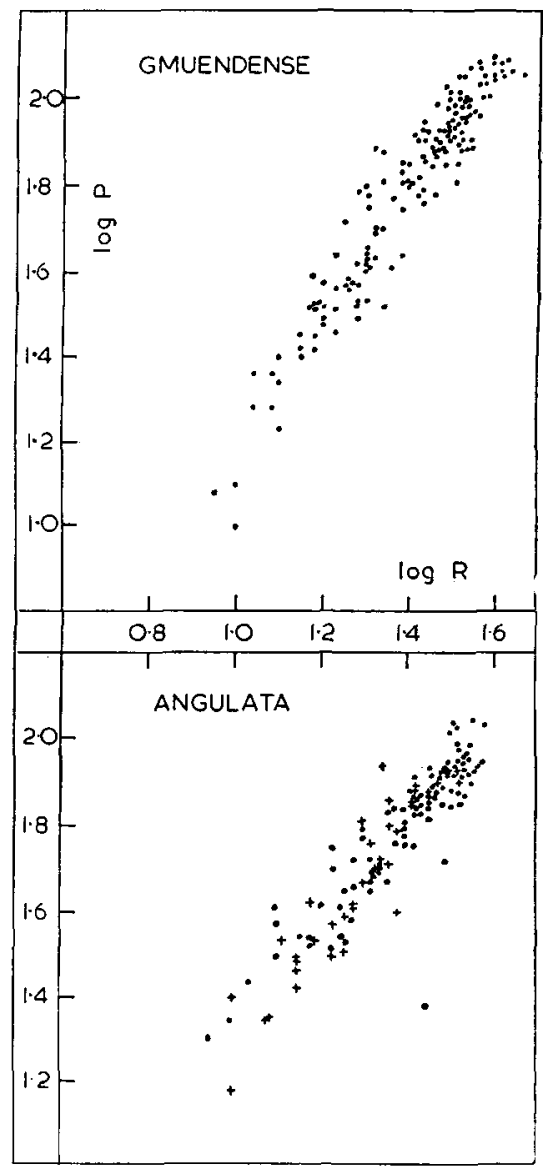

TEXT-FIG. 1.-Scatter diagram to show the relationship between the logarithms of the periphery and length of right valve, measured in $\mathrm{mm}$., in Gryphea samples from the angulata and gmuendense Sub-zones of Glamorgan, etc. The material from Dorset is indicated by crosses.

in terms of three or four $\frac{1}{4}$ whorl units. Granted, it suffers from the deficiency that variation in the earliest stages of coiling in highly incurved forms may be missed, but this is not critical in the circumstances. There is a danger that too much may be read into what Trueman had in mind. He was not particularly concerned, as I see it, with subtle variations in the first few $\mathrm{mm}$. of growth; there is indeed no reference in his paper to the practical difficulties 
involved in assessing variation in the earliest stages of highly incurved forms. No problem arises, furthermore, in comparing his drawings $1 \mathrm{~b}$ and $1 \mathrm{~d}$.

Joysey also makes the point that Swinnerton's (1939) material contained, unlike mine, a high proportion of individuals with area of attachment exceeding $2 \mathrm{~mm}$. This may be partly due to his collection having come from localities I have not visited. The point is, however, not relevant, since I rejected none of the oysters $I$ collected and my results must be considered on their own merits. Given samples from different horizons with small attachment areas, important differences should be recognizable if Trueman were only approximately correct.

As regards my results, both Joysey and Swinnerton (1959) have commented on the fact that I lumped together collections from the country as a whole. Although I have made an answer to this objection in my reply to Swinnerton (1959b) I recognize that my case would be strengthened if I could demonstrate that the facts do not support the evolutionary hypothesis even in Trueman's collecting area in the south-west. I have therefore undertaken a further statistical analysis with some of my original data. The technique is the same as that outlined in my earlier paper, using the shortened methods of calculation described by Imbrie (1956).

Trueman's work is based upon collecting done in Glamorgan and Somerset (precise localities were not specified). All my relevant material from the gmuendense Subzone came from the Glamorgan coast between Southerndown and Gwter Fawr. Most of the specimens from the angulata Subzone were collected either from the Glamorgan coast between Southerndown and Stout Bay or from a quarry at Corston, in north Somerset. As the sample (90) is rather small in comparison to that from the gmuendense Subzone, some forty specimens from Lyme Regis have been included. It seems quite legitimate to add material from Dorset to the rest, since Trueman based his ideas on specimens collected from two different counties and Lyme Regis is hardly greater in distance (some fifty miles) from the collecting localities in Glamorgan than are the Lower Lias localities in Somerset. In all areas the facies at the relevant horizon is an off-shore one of alternating calcilutites and argillaceous beds; differences between Dorset and Somerset are especially hard to detect. Nevertheless, to counter possible objection to this pooling of material, data on the Dorset gryphaeas are shown separately on the graphs (Text-figs. 1 and 2) so that readers may judge for themselves whether or not the specimens fall into the same morphological group as those from Glamorgan and Somerset.

In Text-fig. 1 the logarithms of the periphery (P) and the length of the right valve (R) are plotted as before; the relevant statistics are given in Table 1 .

TABLE 1

\begin{tabular}{|c|c|c|}
\hline & $\begin{array}{c}\text { angulata } \\
\text { Subzone. }\end{array}$ & $\begin{array}{l}\text { gmuendense } \\
\text { Subzone. }\end{array}$ \\
\hline $\mathbf{N}$ & 130 & 151 \\
\hline$y$ & $1 \cdot 76$ & $1 \cdot 78$ \\
\hline 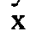 & $1 \cdot 37$ & $1 \cdot 39$ \\
\hline $\mathbf{S}_{\mathbf{y}}$ & 0.190 & 0.222 \\
\hline$S_{\mathbf{x}}$ & $0 \cdot 144$ & 0.154 \\
\hline $\mathbf{r}$ & $0 \cdot 891$ & 0.895 \\
\hline $\mathbf{a}$ & $1 \cdot 32$ & $1 \cdot 44$ \\
\hline b & -0.04 & -0.22 \\
\hline & 0.053 & 0.053 \\
\hline
\end{tabular}

For Trueman's hypothesis to be confirmed, the slope $a$ should be significantly greater for the sample from the gmuendense Subzone. In fact there is no significant difference in slope between the samples $(P>0.05)$. There is moreover, no significant positional difference. As Joysey thinks that breadth 
of the left valve is the most suitable index of size and as Swinnerton has questioned my choice of valve length for this purpose I have also plotted the logarithms of the periphery against logarithms of the breadth of the left valve (B) with the same material (Text-fig. 2 and Table 2 ). Once more, there

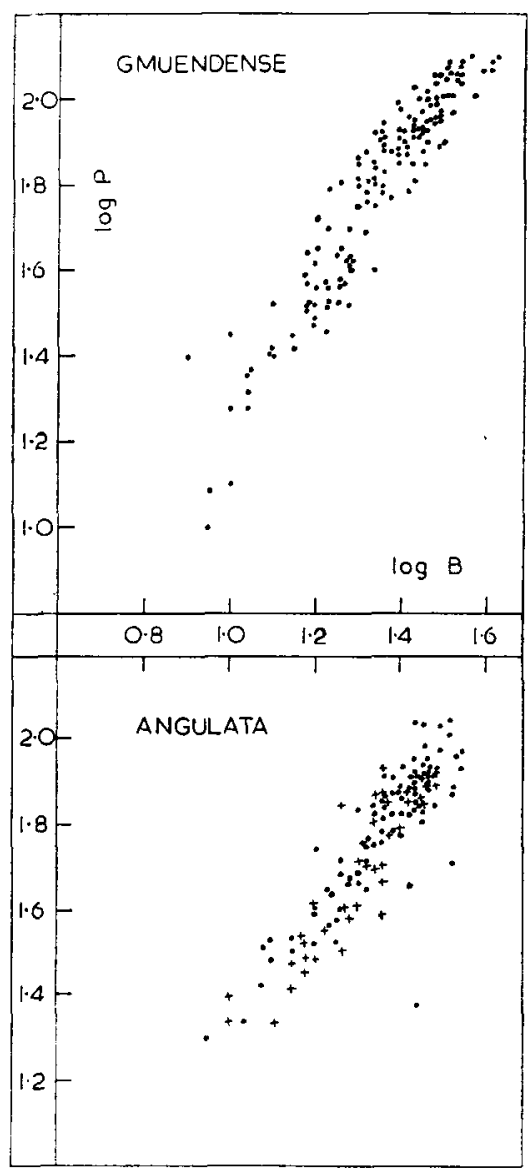

TexT-FIG. 2.-Scatter diagram as in Text-fig. 1 to show the relationship between the logarithms of the periphery and breadth of the left valve.

is no significant difference in either slope or position ( $\mathrm{P}>0.05)$; the results are indeed very similar to those obtained using $\mathbf{R}$ as the size index.

Trueman's hypothesis is a good one in that it makes a claim of pronounced changes which is readily amenable to a simple test, pace Dr. Joysey. Differences of detail might be allowed, but any revised version of the hypothesis should follow the broad pattern Trueman outlined. The facts $I$ have gathered in my statistical investigations are at variance with the hypothesis 


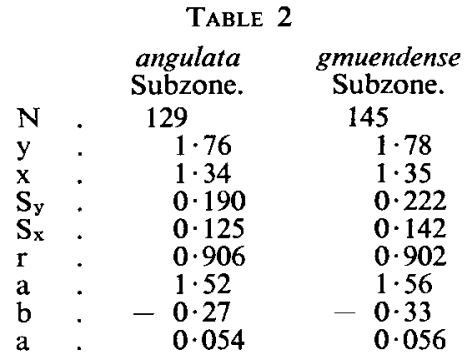

that coiling becomes markedly tighter up the Liassic succession but accord with the alternative hypothesis in which Gryphaea is regarded as a single, distinct Linnaean species (G.arcuata) which underwent no change except that due to a slight increase in size. It seems more reasonable therefore to reject Trueman's hypothesis in favour of the alternative than to postulate a subtle change, manifested only in the young stages, which cannot readily be detected by practicable methods of measurement.

\section{REFERENCES}

Hallam, A., 1959a. On the supposed evolution of Gryphaea in the Lias. Geol. Mag., xcvi, 99-108.

1959b. The supposed evolution of Gryphaea. Ibid., xcvi, 419-420.

IMBRIE, J., 1956. Biometrical methods in the study of invertebrate fossils. Bull. Amer. Mus. Nat. Hist., 108, 217-252.

Joysey, K. A., 1959. The evolution of the Liassic oysters Ostrea-Gryphaea. Biol. Rev., xxxiv, 297-332.

Swinnerton, H. H., 1939. Palaeontology and the mechanics of evolution. Quart Journ. Geol. Soc., xcv, xxxiii-lxx.

1959. Concerning Mr. A. Haliam's article on Gryphaea. Geol. Mag., xcvi, 307-310.

Grant Institute of Geology,

A. Hallam.

\section{West MAINS ROAD,}

EDINBURGH.

SiR,-In my review (1959) I criticized the statistical part of Hallam's investigation (1959a) on two main grounds: namely that the length of the periphery of the left valve of Gryphaea is not a suitable measure of coiling, and that the samples consisted of material pooled from several localities. In the foregoing letter Hallam has attempted to answer these criticisms and has presented some additional statistical work in support of his original conclusions. I wish to maintain that my criticisms are justified in relation both to his original and to his present work.

Hallam's graphs show the relationship between the length of the right valve and the length of the periphery of the left valve. These graphs are simply a plot of one size dimension against another, but they are not graphs of the relationship between size and the amount of coiling. This is so because the length of the periphery of the left valve is not a measure of coiling unless the periphery of that shell has the form of a logarithmic spiral, and this is demonstrably not the case. (Maclennan and Trueman, 1942.) 
Trueman (1922) stated that: "The arching of the left valve increases until it is coiled through more than one and a half whorls." Trueman's graph is graduated in terms of whorls, and this measure of coiling is directly comparable with Swinnerton's measure (1932) in terms of the " angle of rotation ", which he apparently measured to the nearest 5 degrees. In contrast, Hallam refers to the length of the periphery of the left valve as though it were a measure of coiling, although it is in no way comparable with that used by Trueman. This is illustrated in Text-fig. 1 which shows two profiles that are identical both
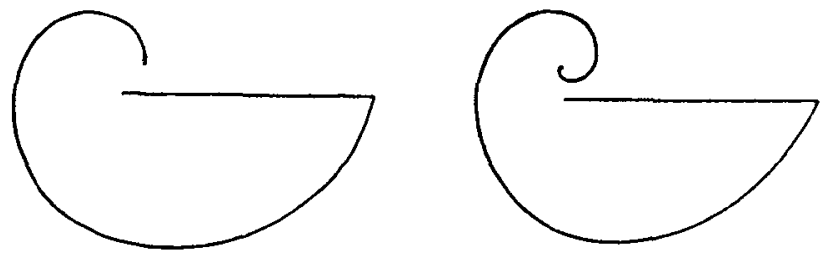

TeXT-FIG. 1.-Two profiles which are identical both in the length of the periphery of the left valve and in the length of the right valve, but which differ in the amount of coiling ( $\frac{3}{4}$ and $1 \frac{1}{4}$ whorls). The small area of attachment indicates the original orientation of the shell.

in the length of the periphery of the left valve and in the length of the right valve, but which differ in the amount of coiling. If Hallam insists upon using an approximate measure of coiling which does not distinguish between shells differing in the total amount of coiling, then any possible difference between the two samples may easily be obscured, and the fact that he finds " no significant difference " has no meaning.

In the foregoing letter, Hallam's comparison of the $P / R$ ratio of his angulata Subzone sample with that of Trueman's Fig. 1b appears to be somewhat misplaced. Fig. $1 \mathrm{~b}$ is an illustration of Gryphaea dumortieri, a species which Hallam (1959a, pages 105-6) has previously dismissed as a mere phenotypic variation of Liostrea irregularis, under the name $L$. irregularis, var. dumortieri. Hallam has previously pointed out that measurement of the periphery would not be satisfactory as a means of comparing Liostrea and Gryphaea (1959a, p. 100). Furthermore, he stated that L. irregularis is sharply replaced by $G$. incurva just below the top of the angulata Zone (pp. 106-7), whereas his own sample was collected from the highest part of the angulata Zone (p. 100).

Hallam rightly states that Trueman's hypothesis is based upon a consideration of the adult organism, but he appears to forget that the adult shell represents the whole life history, including those parts laid down during the juvenile stages. It is inescapable that Trueman's assessment of the total coiling of an adult shell included coiling during juvenile stages. If Hallam chooses to discount the importance of the juvenile stages, and uses a method which obscures differences in the amount of coiling of the umbo, then he will inevitably obscure any possible difference between his samples.

Hallam has noted that his samples, unlike Swinnerton's (1939) collections, do not contain many individuals with an area of attachment exceeding $2 \mathrm{~mm}$., and has suggested that this may be partly due to the collections having come from different localities. Contrary to Hallam, $I$ regard this point as being relevant, insofar as it illustrates the importance of phenotyphic variation in this oyster material.

I maintain that in the present case it is bad practice to pool samples from different localities and treat them as though they were drawn from a single population. There is substantial evidence that the relationship between size and coiling is subject to phenotypic variation, and the factors responsible for 
phenotypic variation may not be reflected in the sediments. If, as seems likely, phenotypic differences are superimposed upon the supposed evolutionary sequence, then one can hardly hope to elucidate the problem by using coarse sampling methods. Referring to Hallam's present graphs, I agree that readers must judge for themselves whether the dots and crosses have the same trend, line or whether perhaps the crosses tend to lie towards the right of the dots in the lower part of the scatter.

In his additional statistical work Hallam has used the breadth of the left valve as an alternative size dimension, but finds little difference from his previous results. This improvement in the choice of the size dimension is wasted unless he also abandons the length of the periphery of the left valve as a measure of coiling.

I concluded my previous article (1959) on this subject with the statement: "Reviewing the various quantitative methods which have been applied to the study of the Ostrea-Gryphaea series has led me to the opinion that most of the statistical evidence is open to criticism and does not provide a sound basis for any conclusion. Until further evidence on the relationship between size and coiling becomes available, the only possible verdict is Not Proven." Despite Hallam's additional statistical work, I still hold this opinion. With reference to the statistical evidence it is impossible to judge whether it is Trueman or Hallam who has reached the right conclusion for the wrong reasons.

Some who have read my Biological Review article have expressed regrets that I reached no conclusion. But this is not correct. I concluded that the available evidence does not justify most of the conclusions which have been drawn by previous workers. I used the existing data to make a number of suggestions, and drew attention to some of the difficulties which would inevitably arise in the interpretation of the results of any further investigation. It is true that I reached no solution to the Gryphaea problem. This raises the question whether any solution is possible. Oysters are notoriously variable and few would regard them as ideal material on which to base a study of an evolutionary series. In the present case it is demonstrable that the extent of phenotypic variation at the top of the succession is comparable with the supposed evolutionary change throughout the succession. Under these circumstances one must be realistic and accept that the Liassic OstreaGryphaea series is intrinsically unsuitable material for this type of investigation. While it might be instructive to try to obtain some more data on the relationship between,size and coiling, the results of any further work are likely to be amenable to more than one interpretation.

\section{ADDITIONAL- REFERENCES}

Maclennan, R. M., and A. E. Trueman (1942). Variation in Gryphaea incurva (Sow.) from the Lower Lias of Loch Aline, Argyll. Proc. Roy. Soc. Edinb., B, 61, 211.

Swinnerton, H. H. (1932). Unit characters in fossils. Biol. Rev., vii, 321.

Trueman, A. E. (1922). The use of Gryphaea in the correlation of the Lower Lias. Geol. Mag., lix, 256.

UNIVERSITY MUSEUM OF ZOOLOGY,

K. A. Joysey.

DOWNING STREET,

Cambridge.

\section{"DELTAIC" CYCLOTHEMS}

SIR,-In principle, steady even subsidence by itself seems capable of determining the birthplace and subsequent cyclothemic life-history of a "delta". No more need be put into a general theory. All "deltas" can be considered as possessing innate tendencies to overlengthen and short-circuit 